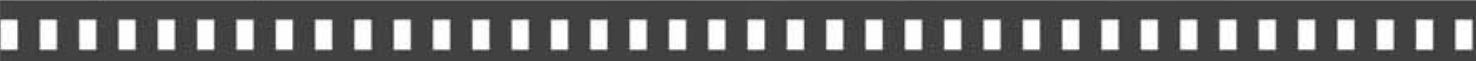

\author{
Entrevista: \\ MiguelChikaoka
}

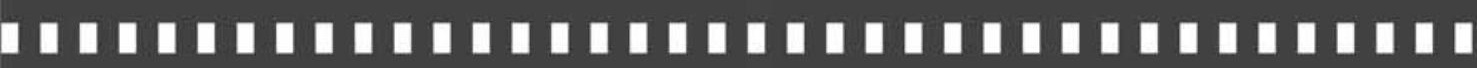

Beatriz Sallet 


\section{“O educador não está preparado para trabalhar com o turbilhão da produção fotográfica digital”}

Beatriz Sallet*

Miguel Chikaoka critica a velocidade tecnológica, a velocidade da devastação ambiental, do planeta, dos valores e, por isso, a devastação crítico-cultural. Em Porto Alegre, o fotógrafo, nascido em Registro (SP), em 1950, adverte para outra séria constatação: na atualidade, é de pelo menos cinco anos a defasagem de conhecimento tecnológico enfrentada por educadores do campo da fotografia, com relação aos jovens e adolescentes da Era digital.

Engenheiro eletrotécnico formado pela Universidade Estadual de Campinas (Unicamp), Chikaoka desistiu do doutorado, que fazia na área de engenharia, na França (entre 1976 e 1979), para abraçar de vez o mundo das imagens. Depois de aprender sobre fotografia em Nancy e Paris, voltou para o Brasil, em 1980, e escolheu Belém do Pará para viver.

Crítico ferrenho da velocidade da devastação do planeta concomitante à dos valores dominantes do mundo atual, desde o início de sua carreira como fotógrafo esteve engajado em movimentos sociais, políticos e culturais da região norte. Fundou a agência Kamara Kó, voltada ao fotojornalismo, às reportagens e aos trabalhos de documentação das questões sociais e ambientais da Amazônia.

Fotojornalista e documentarista, Chikaoka colaborou com jornais como Movimento e Resistência, da Sociedade Paraense de Defesa dos Direitos Humanos; e da Agência F4. Integrou o corpo

* Jornalista, fotógrafa e professora de fotografia. Mestre em Comunicação pela Universidade do Vale do Rio dos Sinos - Unisinos. Doutoranda em Comunicação pela mesma instituição. 
editorial das Revistas Cuíra, da Universidade Popular de Belém do Pará, e Gibi, da Agência Emaús. Trabalhou junto ao Movimento Nacional de Meninas e Meninos de Rua e à Unicef (United Nations Children's Fund - Fundo das Nações Unidas para a Infância), para a realização de um documentário sobre a realidade da criança e do adolescente no interior da Amazônia.

Em 1984, um marco em sua carreira: idealizou e - com o apoio da Fundação de Amparo ao Desenvolvimento da Pesquisa da Universidade Federal do Pará e da Fundação Nacional da Arte do Ministério da Cultura - coordenou o projeto "Fotoativa”, cujo principal objetivo era promover o desenvolvimento do ensino-aprendizagem e da pesquisa em fotografia. Pouco mais de duas décadas de intensa atuação da Fotoativa na cena cultural e política foram decisivos para projetar Belém do Pará como referência no contexto da fotografia brasileira contemporânea.

Em visita a Porto Alegre, em agosto de 2010, Chikaoka ministrou uma oficina de fotografia para um grupo de fotógrafos, educadores e estudantes, no Centro de Cultura Quilombo do Sopapo, no Bairro Cristal. Nesse local, tive o privilégio de conhecer um pouco do belo trabalho social por ele desenvolvido.

Chikaoka insiste que o ensino da fotografia precisa ser imediatamente repensado. Defende que os professores desloquem a atenção dos artefatos mais portáteis e que reflitam a reeducação para a fotografia: "não devemos pensar na fotografia como produto final, mas em todo o processo que a envolve. Devemos pensar e refletir sobre a percepção da luz em toda sua amplitude e possibilidades”, alertou durante a oficina.

A entrevista que segue foi concedida no Mercado Público de Porto Alegre, local escolhido pelo próprio Chikaoka: “conheço uma cidade quando conheço seu mercado público”, ensinou. 


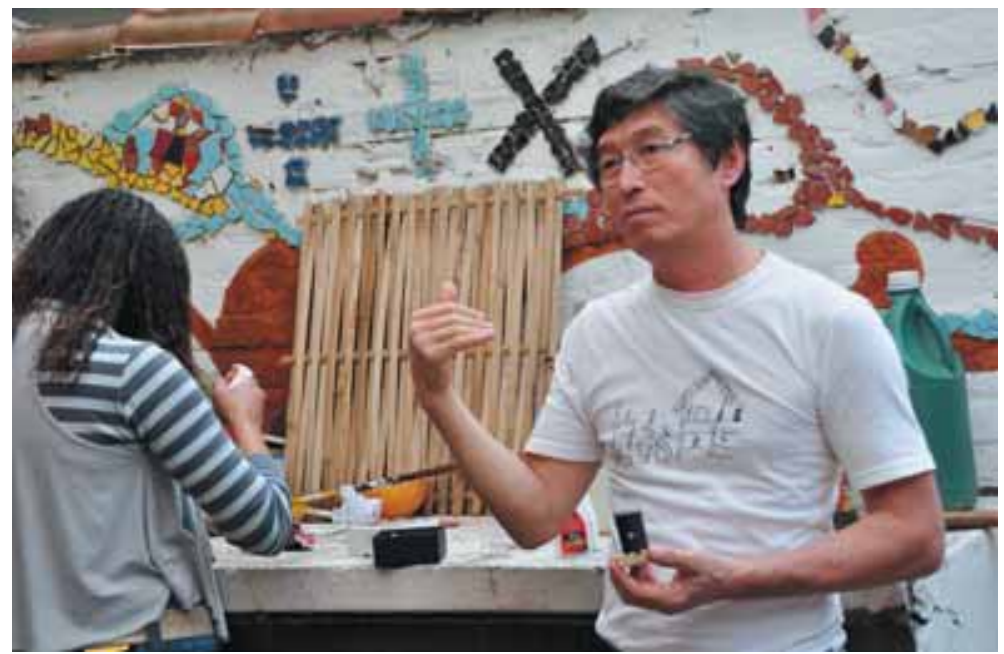

Miguel Chikaoka durante oficina que ministrou em Porto Alegre

Fotografia: Beatriz Sallet

Fonte: Acervo pessoal de Beatriz Sallet

\section{Entrevista}

Beatriz Sallet - Miguel, por que tu falas que não devemos pensar a fotografia apenas como produto final?

Miguel Chikaoka - Porque ficou muito fácil obter uma imagem "tecnicamente perfeita" numa escala industrial, em detrimento da compreensão e abordagem da essência do processo que resulta na imagem fotográfica. Atualmente, o educador não está preparado para trabalhar com o turbilhão de imagens que invadem o ambiente escolar, decorrentes do uso de equipamentos fotográficos de fácil acesso como, por exemplo, os compactos de baixo custo e os celulares. Dada a velocidade com que os avanços tecnológicos são incorporados nas câmeras fotográficas, o professor encontra-se em defasagem de alguns anos em relação ao que resulta da disseminação e uso desses aparatos nos contextos educacionais onde ele atua. É necessário pensar numa reeducação, tentar deslocar a atenção e não falar em fotografia focada somente na imagem. A diferença é enxergar, explorar e construir os saberes com o processo. 
Beatriz Sallet - Como enxergar esse processo? Como reeducar em um momento em que se vive esse turbilhão de imagens?

Miguel Chikaoka - Fugindo da educação da fotografia útil, dos valores impostos pelo sistema. Devemos pensar a educação no sentido amplo, para o exercício da cidadania plena, planetária e, nela, a fotografia com outra percepção, como processo, com o todo o potencial, que não é trabalhado. Falar da luz, perceber a luz. Pensar fotografia na educação através da luz, por exemplo, e não a partir da imagem. Vejo problemas na educação voltada para uma formação visando uma produtividade enquadrada pelos valores dominantes. Estamos num beco sem saída e teremos que frear e agir de outra maneira. Os avanços tecnológicos melhoram o rendimento, mas o seu uso desenfreado, sem ponderação, condiciona e atropela o "nosso" tempo. A velocidade dessa "evolução" é alarmante, pois potencializa o consumismo desenfreado e leva à insuportabilidade do planeta. Consome-se o planeta, e sabemos que isso tem um limite, que nada na natureza é inesgotável. Falo assim com base nos valores que norteiam o meu pensamento, valores humanos, de formação que recebi desde a minha família. Com os meus pais aprendi a me perguntar sempre: para que estou aqui?

Beatriz Sallet - Fale um pouco da sua formação.

Miguel Chikaoka - Tenho formação acadêmica na área de exatas, em engenharia eletrotécnica. Estudei na Unicamp, sem dúvida uma boa referência, mas eu não via uma luz no fim do túnel. Algo me dizia que essa realização profissional não corresponderia aos meus ideais, mas concluí o curso e consegui uma bolsa para o doutorado. Foi aí que surgiu a fotografia, para extravasar a minha angústia de perceber o mundo e a mim mesmo. Optei pela fotografia sem saber ainda o que ela poderia ser para mim, mas decidi que não iria mais continuar com a engenharia. Embora minha mãe se sentisse chocada por estar abandonando uma carreira, "jogando fora” anos de estudos, para mim significava uma retomada dos valores humanos essenciais que aprendi com os meus pais. Atualmente, nas minhas práticas educativas, percebo que o processo nasceu lá na minha infância, no seio da família e da comunidade onde cresci. E o aprendizado continua. 
Beatriz Sallet - Então, a fotografia chegou como a luz no fim do túnel?

Miguel Chikaoka - Sim. Comecei a fotografar em 1977, quando fui para a França, para a cidade de Nancy, fazer doutorado em engenharia. Fui porque ganhei uma bolsa, mas sabia que não era o degrau que eu queria subir. Na época, comecei a fotografar com o intuito de registrar as minhas andanças por lá. Memória das viagens que fazia pela França e pela Europa. Por coincidência, no porão da residência universitária onde eu morava tinha um laboratório fotográfico, onde funcionava o Foto Clube dos Residentes. Entrei nesse fotoclube e fiz a revelação dos meus primeiros filmes com a orientação dos colegas. Foi a gota d'água. A partir daí passei a fotografar e frequentar o laboratório quase que compulsivamente. Três meses depois fui convidado a mostrar os meus trabalhos numa exposição do clube e pude perceber que os meus sentimentos ecoavam junto ao público, descobri uma nova linguagem através da qual poderia me expressar. $\mathrm{E}$ aí virei rato de exposição. Ia de Nancy a Paris só para ver exposições fotográficas, passava os finais de semana inteiros fazendo isso, durante três anos. A França me deu essa oportunidade de me descobrir fotógrafo, de descobrir o meu caminho. Com isso, perderam um engenheiro, mas ganharam um fotógrafo.

Beatriz Sallet -E o fotógrafo educador quando surgiu?

Miguel Chikaoka - Então, voltei para o Brasil decidido a viver da fotografia e conhecer o país por outro ângulo, distante da minha terra natal. Escolhi morar em Belém, trabalhar como repórter fotográfico e com muita vontade de continuar o aprendizado. Foi quando fui convidado a ministrar uma oficina de fotografia em uma escola de arte, e isto em um momento - início dos anos 80 - em que estavam todos saindo dos "anos de chumbo". Ali comecei a desenvolver atividades e oficinas. Não parei mais, pois descobri que assim poderia continuar exercitando e compartilhando o meu aprendizado, sem a pretensão de formar profissionais, mas de pensar e refletir sobre o fazer fotográfico. 


\section{Beatriz Sallet - Daí nasceu a Fotoativa?}

Miguel Chikaoka - Sim, a Fotoativa é o desdobramento de experiências coletivas, como o FotOficina e o FotoPará, que nasceram a partir da oficina na Escola de Arte Ajir. Todas guardam em comum o propósito de reunir pessoas em torno do aprendizado e da prática da fotografia e da reflexão do fazer fotográfico em todas as suas possibilidades e dimensões. Nessas duas décadas e meia de atuação, construímos uma base metodológica norteada por uma visão transversal, reunindo práticas e vivências mobilizadoras dos sentidos, de forma que o pensamento fotográfico se estenda para além da imagem fotográfica em si. A trajetória dos raios de luz que formam a imagem numa câmera obscura pinhole, por exemplo, é “desenhada” através de jogos e brincadeiras que mobilizam os indivíduos de forma integral e lúdica de tal forma que, além de despertar a curiosidade sobre o fenômeno e criar um ambiente ideal para trabalhar conhecimentos sobre a natureza física da luz, essa vivência remete-os a fazer leituras e reflexões sobre o universo simbólico da luz. A construção dessas dinâmicas visa, ainda, facilitar o envolvimento e interação de grupos constituídos por indivíduos com os mais diferentes perfis, seja quanto ao nível de escolaridade, seja quanto às origens sociais e culturais. No momento, tento introduzir essas abordagens junto aos educadores, visando a sua aplicação no ambiente do ensino fundamental.

Beatriz Sallet - Trata-se realmente de uma visão aberta e que permite pensar o ensino de uma forma avessa ao ensino formal da fotografia, como tu mesmo disseste, daquele ensino que visa apenas o produto final?

Miguel Chikaoka - Exatamente. Não acho apropriado falar de fotografia como disciplina de sala de aula, mas introduzir essas abordagens como uma alternativa pedagógica potencializadora do aprendizado amplo e irrestrito, voltado para a formação de base do cidadão. Acho que a base do ensino fundamental, segmentada por disciplinas, desloca a função da escola nessa fase da formação. O objetivo deve ser a formação para o exercício pleno da cidadania de direitos e responsabilidades pautados numa visão planetária. Não como modismo, por indução midiática, mas 
com consciência plena. Educação ambiental e certificações ISO são valores a posteriori que comprovam que o “dever de casa” não foi realizado.

Beatriz Sallet - E para os portadores de necessidades especiais, deficientes auditivos, visuais e mudos, tua experiência com oficinas tem muito a ensinar, a multiplicar? (Aqui, lembrei da oficina que recentemente cursei com o Miguel, quando construímos caixas de luz, e que ele pediu silêncio absoluto enquanto realizávamos o trabalho manual. Pediu que olhássemos e fizéssemos o que ele estava fazendo, apenas observando. Ele contou que foi daquela maneira que aprendeu a chegar onde os surdos estavam, ou pelo menos próximo).

Miguel Chikaoka - Para pensar e trabalhar com os surdos, mudos ou cegos precisamos desafiar a nossa capacidade de percepção. Não faz sentido querer que os cegos cheguem onde chegamos; nós é que devemos chegar onde eles chegaram. Ou seja, trata-se de aprender com eles, como eles resolvem o que nós, "normais", perdemos a capacidade de resolver. No fundo a questão da inclusão, pelo menos na educação, deve ser inversa. O modelo de educação predominante ainda é compulsório, competitivo, fragmentado e reducionista, e a prática da solidariedade institucionalizada é assistencialista, prepotente e midiática. Edgar Morin, em A cabeça bem feita, ensina que "a aptidão para contextualizar e integrar é uma qualidade fundamental da mente humana, que precisa ser desenvolvida, e não atrofiada" e que "uma inteligência incapaz de perceber o contexto e o complexo planetário fica cega, inconsciente e irresponsável.” Não há dúvida de que a nossa atrofia face à sustentabilidade planetária é fruto do processo de fragmentação do conhecimento pautado na separação das disciplinas, na compartimentação dos saberes. Repensar a nossa relação ensinoaprendizado significa repensar e exercitar a nossa capacidade de construção do conhecimento amplo, sem a ruptura da natureza rizomática dos sentidos e do sentido dessa construção. 